\title{
Desenvolvimento rural, capitais intangíveis e atores locais: reunião de exemplos empíricos
}

\author{
Tatiane Salete Mattei ${ }^{1}$ \\ Taíse Fatima Mattei ${ }^{2}$
}

\begin{abstract}
RESUMO
Por desenvolvimento rural se entende as ações e práticas que visam reduzir a pobreza rural e valorização dos recursos locais. Engloba aspectos sociais, culturais, técnicos, econômicos e a participação ativa da população. Os atores locais são os protagonistas do desenvolvimento e os capitais intangíveis, principalmente o capital social, materializado na cooperação, associativismo, confiança e engajamento, são fatores decisivos para alcançá-lo. $\mathrm{O}$ trabalho objetivou, através de uma pesquisa bibliográfica, reunir exemplos empíricos que mostram a atuação e contribuição dos atores locais e a presença dos capitais intangíveis em diversas comunidades brasileiras. Nos casos apontados se verificou a presença de capitais intangíveis e o protagonismo dos atores locais, assim como iniciativas que aproveitaram as potencialidades dos locais para gerar desenvolvimento. Os casos refletem a realidade do novo rural brasileiro, pautado na diversificação e pluriatividade como forma de aumento de renda, emprego e permanência da população no campo.
\end{abstract}

Palavras-Chave: novo rural; capitais intangíveis; atores locais.

\section{Rural development, intangible capital and local actors: gathering empirical examples}

\begin{abstract}
Rural development means actions and practices aimed at reducing rural poverty and valuing local resources. It encompasses social, cultural, technical, economic aspects and the active participation of the population. Local actors are the protagonists of development and intangible capital, especially social capital, materialized in cooperation, associations, trust and engagement, are decisive factors to achieve it. The work aimed, through a bibliographical research, to gather empirical examples that show the performance and contribution of local actors and the presence of intangible capital in several Brazilian communities. In the cases mentioned, the presence of intangible capital and the leading role of local actors were verified, as well as initiatives that took advantage of the potential of the places to generate development. The cases reflect the reality of the new Brazilian rural, based on diversification and pluriactivity as a way to increase income, employment and the population's permanence in the countryside.
\end{abstract}

Keywords: new rural; intangible capital; local actors.

\section{INTRODUÇÃO}

O modelo agrícola produtivista, assentado nos princípios da Revolução Verde da década de 1960, representado por uma nova fase do progresso tecnológico e financeiro do capital, desencadeou profundas mudanças sociais, políticas e econômicas no meio rural, principalmente para pequenos agricultores menos capitalizados, como redução de renda, abandono do campo e marginalização (SOUZA; ELESBÃO, 2008).

\footnotetext{
${ }^{1}$ Doutoranda do PGDRA da UNIOESTE Campus Toledo-PR. Mestra em Gestão e Desenvolvimento Regional pela UNIOESTE, Campus Francisco Beltrão-PR. Bacharela em Ciências Econômicas pela UNIOESTE, Campus Francisco Beltrão-PR. Pesquisa a área de Economia e Administração, atuando principalmente nos seguintes temas: Eficiência dos Gastos públicos; Desenvolvimento e Crescimento Econômico; Desenvolvimento Regional; Educação e Desenvolvimento; Meio Ambiente, Economia e Sociedade; E-mail: tati_mattei@ hotmail.com

2 Doutora em Teoria Econômica pelo Programa de Pós-Graduação em Ciências Econômicas - PCE - da Universidade Estadual de Maringá. Mestra em Gestão e Desenvolvimento Regional pela Universidade Estadual do Oeste do Paraná (UNIOESTE) campus de Francisco Beltrão. Bacharela em Ciências Econômicas pela Universidade Estadual do Oeste do Paraná (UNIOESTE) campus de Francisco Beltrão. Professora Substituta no Instituto Federal do Paraná, campus de Palmas. E-mail: taise.mattei.slo@gmail.com
} 
A partir do final de 1980, em oposição aos projetos voltados ao agribusiness, surge uma nova perspectiva para o mundo rural, centrada nos atores locais, na diversificação das atividades agrícolas e na pluriatividade como estratégia de reprodução econômica e social (OLIVEIRA; MELLO, 2006).

A nova perspectiva do desenvolvimento valoriza as potencialidades endógenas dos territórios. O desenvolvimento rural é resultado da valorização dos recursos locais e engloba aspectos sociais, culturais, técnicos, econômicos e a participação ativa da população (NATÁRIO; BRAGA; REI, 2010). Cabe aos agricultores, nesta nova perspectiva, não apenas a produção agropecuária, mas o processamento de produtos naturais e a inserção de atividades não agrícolas como culinária, artesanato, cultura, turismo e geração de energia, o que vem sendo chamado de novo rural (STRASSBURG et al., 2015).

Os atores locais são os protagonistas do desenvolvimento territorial rural e as variadas formas de capitais intangíveis existentes (capital social, capital humano, capital institucional, capital cívico e empreeendedorismo) constituem fatores de produção altamente decisivos. As regiões dotadas desses fatores ou que estiverem estrategicamente direcionadas para desenvolvêlos terão as melhores condições de atingir um desenvolvimento acelerado e equilibrado (PIACENTI, 2016).

Dada a importância dos atores locais e dos capitais intangíveis para o desenvolvimento rural surgiu a problemática da pesquisa: Qual a atuação e contribuição dos atores locais e dos capitais intangíveis para o desenvolvimento de comunidades rurais brasileiras? Dessa forma o trabalho objetiva, através de uma pesquisa bibliográfica, reunir exemplos empíricos que mostrem a atuação e contribuição dos atores locais e a presença dos capitais intangíveis em diversas comunidades rurais.

Os casos apresentados buscam apontar a presença dos capitais intangíveis e a ação dos atores locais em diversas esferas como o turismo rural espiritual, feiras de produtores familiares, turismo rural, enoturismo, agroindústrias e turismo cultural rural, caracterizando exemplos do novo rural brasileiro.

O presente trabalho se diferencia dos demais por varrer a literatura e reunir resultados de diversos estudos de caso em um único trabalho. Objetiva ser um trabalho referência no meio acadêmico na busca por exemplos empíricos sobre a presença dos capitais intangíveis, principalmente o capital social, e a importância do protagonismo dos atores locais para o desenvolvimento rural. Este trabalho facilitará o entendimento de alunos que não possuem experiências e vivencias sobre o novo contexto rural brasileiro. Além disso, servirá de motivação para atores e formuladores de políticas para acreditarem, incentivarem e investirem em ações locais.

Além desta introdução o trabalho apresenta na segunda seção um apanhado bibliográfico sobre o desenvolvimento territorial endógeno e os elementos do desenvolvimento endógeno, na terceira o referencial sobre o desenvolvimento rural e na quarta seção é apresentado casos empíricos sobre a atuação dos atores locais e a presença dos capitais intangíveis. Na seção cinco se encontra as considerações finais e por fim as referências utilizadas.

\section{DESENVOLVIMENTO TERRITORIAL ENDÓGENO}

$\mathrm{Na}$ busca por respostas para a heterogeneidade do desenvolvimento regional, encontram-se diversas teorias na literatura, como a teoria com ênfase nos fatores de aglomeração (chamada de exógena), vigente do final do século XIX até meados do século XX, e a abordagem mais recente, que valoriza as características endógenas do território (NATÁRIO; BRAGA; REI, 2010). 
O desenvolvimento baseado em fatores exógenos aponta intervenções vindas do alto, externas ao espaço de referência, conhecido como "do alto para baixo", vindas seja do Estado ou da iniciativa privada de outras regiões. Os espaços cativam interesse externo de acordo com atrativos presentes, como disponibilidade de recursos naturais, qualificação da mão de obra, proximidade com mercados maiores ou pela disponibilidade de recursos governamentais (FERRERA DE LIMA, 2017).

O Estado, nesse modelo, é essencial para o surgimento de novos mercados através de investimentos em infraestrutura, novos produtos e estímulo ao empreendedorismo. Em vários lugares do mundo foram elaboradas políticas baseadas na aplicação de pólos de crescimento e na dinâmica de atração de investimentos dotados de grande poder de irradiação cujo objetivo era a superação do subdesenvolvimento através da industrialização. As ações do Estado se justificavam pela necessidade de viabilizar o investimento em áreas deprimidas e em setores de elevado risco. Era preciso que o estado assumisse o papel de planejador, tanto em áreas produtivas como nas áreas de saúde, educação, moradia e também financiador do setor privado (LIMA; SIMÕES, 2009).

Este modelo estatal desenvolvimentista levou em consideração apenas o espaço geográfico sem considerar o espaço econômico e as aptidões das respectivas regiões e nem sempre teve efeitos suficientes para desencadear processos de crescimento autosustentados. $\mathrm{O}$ modelo então encontrou seus limites no início da década de 1980, devido também à reversão das condições internacionais (choques do petróleo, aumento dos juros, restrições de financiamento, etc.) e aos desequilíbrios internos (inflação, endividamento, crise fiscal, etc.) (BRUM, 2003; LIMA; SIMÕES, 2009).

Na década de 1990, para entender porque o nível de crescimento das regiões era discrepante, mesmo elas dispondo dos mesmos níveis de fatores produtivos como capital financeiro, mão de obra e tecnologia, surge a teoria do desenvolvimento endógeno procurando respostas nos fatores de dentro dos territórios, também conhecida como "de dentro para fora" (SOUZA FILHO, 2002).

Para compreender a dinâmica do desenvolvimento territorial é importante distinguir inicialmente a ideia de região e território. Região é um instrumento analítico para descrever as características naturais dos espaços, permitindo sua classificação e tipificação. Região tem limites e é possível fazer a regionalização de acordo com diversos critérios como relevo, clima, geologia, localização, entre outros, que caracterizam determinados espaços habitados e utilizados com finalidades econômicas por uma determinada população. A região foi a unidade de referência para medir a riqueza, indicadores econômicos, níveis educacionais e suas evoluções por muito tempo, demonstrando características de crescimento econômico. A partir de meados de 1980 novos critérios de julgamento e avaliação surgem a respeito do desenvolvimento, como sustentabilidade e qualidade de vida e emerge o conceito de território (ABRAMOVAY, 2000a).

O território é o espaço onde transcorrem as relações sociais, econômicas, políticas e institucionais. $\mathrm{O}$ trabalho humano e as interações entre os indivíduos modificam o espaço natural, caracterizando um território. Território é um campo de forças, é uma combinação de poder, forças e ações, é uma construção social (ALVES, 2016). Segundo Pieruccini e Corrêa (2017, pg. 13) "o território é uma reordenação do espaço cuja ordem busca, dentro dos sistemas informacionais, um arranjo pertencente a uma cultura".

Segundo Schneider (2004, pg. 108) "a definição do que se entende por território está assentada na definição das relações dos indivíduos com o espaço em que transcorre sua sociabilidade e suas atividades produtivas e nas formas de apropriação e dominação que decorrem dessas relações". 
O desenvolvimento territorial é um processo de mudança estrutural empreendido por uma sociedade organizada territorialmente que vislumbra as possibilidades de desenvolvimento a partir da utilização dos potenciais econômicos, humanos, naturais e culturais internos, incorporando variáveis como participação e gestão local. Dessa forma, nos locais não atrativos ao capital externo deve-se estimular as forças endógenas (FERREIRA DE LIMA, 2017; DRUCIAKI, 2017).

Os atores locais são os protagonistas do desenvolvimento territorial endógeno e o capital social, capital humano, capital institucional, capital cívico, conhecimento, pesquisa e desenvolvimento (P\&D) constituem fatores intangíveis de produção altamente decisivos. As regiões dotadas desses fatores ou que estão estrategicamente direcionadas para desenvolvê-los, reúnem as melhores condições para atingir um desenvolvimento acelerado e equilibrado (PIACENTI, 2016).

Os fatores endógenos ocorrem pela ação do empreendedorismo individual dos cidadãos ou pela ação das organizações da sociedade civil. Em alguns casos, os empreendedores do território visualizam oportunidades de negócios, mobilizam recursos e desenvolvem ações que resultam em modelos de negócios inovadores com oportunidades de emprego e renda. Em outros casos, são as associações e cooperativas ou outros movimentos sociais que estimulam esses processos (FERRERA DE LIMA, 2017).

O pressuposto mais importante do desenvolvimento endógeno é o potencial de desenvolvimento dos territórios. Este possui um conjunto de recursos como redes de empresas e de relacionamento pessoais que nucleiam pequenos negócios, que apoiados na possibilidade de geração de economias de escala no âmbito local, geram externalidades positivas que podem ser comparadas àquelas geradas pelas grandes empresas (BRAGA, 2001).

Em relação à criação de redes para obtenção das economias de escalas locais, os sistemas locais baseados na cooperação de empresas, através de consórcios, contratos ou alianças estratégicas, possuem a capacidade de gerar lideranças e tornar possível o enfrentamento das incertezas. Além disso possibilitam a redução de custos via intercâmbio de produtos, serviços, conhecimento dos processos de produção e a criação de um ambiente cultural favorável à inovação e ao refinamento dos produtos (BRAGA, 2001).

A sociedade civil e as relações sociais, como solidariedade, civismo, integração social e cooperação (institucional ou voluntária), constituem o principal agente de modernização e de transformação de uma região. Esses valores permitem que a região atinja um crescimento equilibrado e sustentado a longo prazo, sem entrar em conflito e contradição com a base social e cultural já existente (SOUZA FILHO, 2002).

A ideia de capital social e cooperação têm ganhado muita atenção de organismos internacionais nos últimos anos. As nações mais prósperas serão aquelas melhor preparadas para formar cidadãos dispostos a trabalhar colaborativamente e organizados em associações voluntárias entre as instituições. Além disso, capital social e cooperação impulsionam inovações, o que deve ser defendido por políticas públicas (SOUZA FILHO, 2002).

No desenvolvimento endógeno as forças territoriais são dependentes de movimentos que ocorrem na base, como empreendedorismo ou capacidade de mobilização social. Conforme Piacenti (2016) não há desenvolvimento onde não há inconformismo com relação ao mau desempenho dos indicadores econômicos, sociais e de sustentabilidade ambiental. Nesse modelo não se impede ações do Estado, este tem novo papel de fomentador e articulador de políticas de desenvolvimento.

\subsection{Elementos do Desenvolvimento Territorial}

Conforme o conceito de François Perroux, desenvolvimento é uma combinação de mudanças mentais e sociais. Ele só ocorre quando se manifesta na sociedade uma energia capaz 
de canalizar positivamente elementos antes dispersos e quando os indivíduos tomam consciência de seus problemas e se empenham em resolvê-los (DRUCIAK, 2017).

Os atores locais são o principal elemento de ação de um território e possuem determinada quantidade de poder, que varia de acordo com os recursos, conexões e sua organização. As possibilidades e capacidades de poder podem ser ampliadas em decorrência de uma alteração econômica, social, organizacional, política ou por acesso algum tipo de recurso natural. A ampliação das redes de poder pode ocorrer também com a interação entre atores, existência de contatos profissionais e de contatos entre instituições (DRUCIAKI, 2017).

O processo de desenvolvimento depende da capacidade dos atores locais organizaremse socialmente e politicamente em conjunto com as variadas formas de capitais intangíveis existentes, sendo os principais: capital humano, capital social, capital institucional, capital cívico e empreendedorismo (RAIHER, 2017).

Capital humano é a capacidade produtiva que um indivíduo pode adquirir, devido à acumulação de conhecimentos, que podem ser utilizados na produção de riqueza. As atividades que aumentam a produtividade de um indivíduo são a educação formal, conhecimento, as experiências, a alimentação, saúde, ambiente familiar e cultural (VIANA; FERRERA DE LIMA, 2010; RAIHER, 2017).

O aumento no estoque de capital humano aumenta o bem estar social, pois aumenta a produtividade e em decorrência gera aumento de salários, melhora a capacidade empreendedora, possibilita aquisição de informações, migração para melhores oportunidades, etc. (PIACENTI, 2016).

O capital social não é uma característica educacional, como o capital humano. Ele deriva exclusivamente de relações sociais dos atores. Reflete a cooperação, que por meio de trocas de informações, participação política e associativismo. Com o capital social os atores alcançam objetivos que não seria possível individualmente (DRUCIAK, 2017; RAIHER, 2017).

Pode-se caracterizar capital social como um conjunto de normas e valores dos atores a partir de relacionamento conjunto. As principais variáveis do capital social são a confiança, a cooperação e a participação política. Pode-se mensurar o capital social através da participação em associações, clubes, partidos políticos e ações coletivas (RAIHER, 2017).

O capital social não é constituído apenas de instituições formais. As relações de familiares e vizinhança, relações de amizade e relações profissionais, por exemplo, também constituem formas informais de capital social, e elas tomam corpo onde os mecanismos formais não penetram ou suas ações não alcançam (MULS, 2008).

O capital institucional é correlato ao conceito de capital social, porém o conjunto de normas e valores é protagonizado pelas instituições ao invés dos atores sociais. As instituições funcionam como normas, elas exercem peso sobre os objetivos e interesses dos atores sociais, facilitando ações coordenadas. O comprometimento e a participação são fatores essenciais do capital institucional (DRUCIAKI, 2017). O capital institucional tem relação com a flexibilidade organizacional ou resiliência do tecido organizacional, capacidade de realizar acordos, desenvolver a inteligência organizacional e relacionar-se com outros contextos regionais (WESENDONCK, 2017).

As instituições que compõem um território servem de proxies para o estoque de capital institucional. Quando várias instituições buscam objetivos comuns, facilitam o processo de desenvolvimento. Ao contrário, quando não convergem ao mesmo objetivo, inviabilizam a realização de ações (DRUCIAKI, 2017).

O capital cívico está ligado ao exercício da cidadania e democracia. Só se configura capital cívico se em uma comunidade os próprios membros difundem para os outros membros as crenças, valores associativos, preocupação com assuntos públicos e a educação cívica. As 
comunidades com capital cívico exigem um bom governo, cobram serviços públicos eficazes e estão dispostos a agir coletivamente para alcançar seus objetivos (DRUCIAKI, 2017).

Por fim, o empreendedorismo acontece quando um ator local identifica novas oportunidades de negócio, independente dos recursos disponíveis. O perfil empreendedor varia de um território para outro e é fruto do meio em que se vive e das relações sociais. $\mathrm{O}$ empreendedorismo depende do ambiente regulatório, da infraestrutura, do mercado, do acesso ao capital, da inovação, do capital humano e da cultura (RAIHER, 2017).

\section{DESENVOLVIMENTO RURAL}

O desenvolvimento rural também circula entre os dois paradigmas básicos, o desenvolvimento exógeno e endógeno (territorial). As abordagens do desenvolvimento exógeno, vigente até meados de 1980, pautado na Revolução Verde, subordinavam as atividades desenvolvidas no espaço rural às implementadas nas economias urbanas. $\mathrm{O}$ desenvolvimento de produtos, serviços e pesquisa ocorreriam no espaço urbano e ao rural caberia apenas receber tecnologias e insumos e fornecer matérias-primas e alimentos para suprir a máquina produtiva urbana. Os produtores rurais não ofereciam perspectivas para o desenvolvimento econômico ou para o aumento da produtividade, estes tinham apenas papel passivo (ALVES, 2008).

No Brasil, sob a condução dos governos militares, diversos programas foram implantados em regiões pobres, sobretudo Nordeste, com o caráter modernizante. A melhoria do bem estar das populações rurais pobres era entendida como um processo natural do movimento de mudança produtiva da agricultura. A absorção de novas tecnologias e sua difusão levariam a aumentos de produção e produtividade e assim uma suposta associação com aumentos de renda, levando ao desenvolvimento rural (NAVARRO, 2001).

$\mathrm{Na}$ ótica do desenvolvimento exógeno o saber tradicional local, que se organiza em redes menores no contexto doméstico, deveria ser substituído por um conhecimento científico e globalizado, alterando assim as relações sociais do meio rural. Os centros de decisões se afastam do dia-a-dia do agricultor gerando longas redes verticais de poder e controle (ALVES, 2008).

O redescobrimento do desenvolvimento rural deu-se pelo reconhecimento dos problemas criados pela agricultura intensiva e pela multifuncionalidade do espaço rural. Algumas premissas foram levantadas a partir de 1980 e 1990 pela Comissão Européia. A modernização agrícola reduziria o emprego agrícola, mas a população poderia permanecer no seu local praticando atividades não-agrícolas. A situação de desemprego no meio urbano seria um incentivo às pessoas do campo permanecerem na atividade. $O$ espaço rural perderia a característica produtiva, mas outras poderiam ser valorizadas como a função paisagística, turística e ecológica. A perda da função produtiva não deveria ser encarada como falência da produção familiar, mas oportunidade de fortalecimento através da agregação de valor aos produtos aproveitando nichos de mercado. Seria a conversão do agricultor em empresário rural (KAGEYAMA, 2004).

Natário, Braga e Rei (2010), no mesmo sentido, apontam que as regiões rurais, caracterizadas pela idade avançada da população, baixa densidade populacional e distanciamento dos mercados e serviços, enfrentam ainda outros problemas como desemprego agrícola, êxodo e problema de sucessão familiar. No entanto, muitas regiões rurais apresentam potencial econômico não aproveitado, que poderiam ser melhores explorados para melhorar o bem-estar e renda agrícola.

$\mathrm{Na}$ abordagem endógena do desenvolvimento rural, os contextos rurais se entrelaçam e se articulam com outros setores da economia na procura do seu desenvolvimento. A força 
dinâmica do desenvolvimento rural está no aproveitamento dos recursos específicos de uma região (naturais, humanos, culturais), nas empresas e nas iniciativas rurais (NATÁRIO; BRAGA; REI, 2010).

A partir de 1970 já se sentia as mudanças do paradigma da revolução verde e emergia a ideia de que as pequenas propriedades agrícolas seriam o motor do crescimento e desenvolvimento e aos atores locais garantias de parcelas maiores das decisões sobre os modelos técnicos e produtivos. O contexto econômico e político também passou por transformações a partir de 1980 o que levou a certa diminuição das intervenções governamentais no setor agrícola. Essa redução levou os agricultores a buscarem outras alternativas como ONGs, cooperativas, entre outras (ALVES, 2008).

A função das áreas rurais é oferecer produtos e serviços, apoiada numa economia flexível e na pequena escala. Contudo, um dos entraves é a capacidade limitada de atores locais participarem das atividades econômicas, se reunir em grupos e cooperar (NATÁRIO; BRAGA; REI, 2010).

Um elemento chave do desenvolvimento rural é a criação de empregos. No período da industrialização acelerada, a agricultura era fornecedora de mão de obra para as cidades. Com o passar do tempo, o processo se inverteu e o campo atualmente demanda infraestrutura, serviços e empregos que assegurem a retenção da população no meio rural (KAGEYAMA, 2004).

A agricultura familiar foi a mais atingida pela globalização no meio rural. A concentração da produção primária, considerando as tendências futuras de commodities, juntamente com as economias de escala, desenvolvimento tecnológico e financeirização, levaram a redução de renda, abandono do campo e marginalização. As múltiplas funcionalidades que o rural pode exercer é uma possibilidade de reduzir a pobreza rural, sendo uma estratégia de sobrevivência e aumento das oportunidades (KUHN, 2015; SOUZA; ELESBÃO, 2008).

O território rural pode ser dinâmico e alcançar o desenvolvimento se investir na multifuncionalidade, pluriatividade e na multissetoriedade. Como multifuncionalidade se entende as várias funções que o rural exerce como função produtiva, ambiental, ecológica e social. A pluriatividade é entendida como a combinação da atividade agrícola com atividades não-agrícolas por membros de uma mesma unidade familiar. A multissetoriedade são os diversos setores que os atores locais podem atuar como artesanato, processamento de produtos naturais, o turismo rural e a conservação ambiental (STRASSBURG et al., 2015).

Os fatores citados compreendem o que os autores vêm chamando de novo rural, na esfera das novas relações entre o rural e o urbano. O novo rural combina a visão agrícola e produtivista e a visão territorial, por meio do aproveitamento das especificidades locais (STRASSBURG et al., 2015).

O próprio conceito do que é rural vem mudando. O rural deixa de ser o lugar que não é urbano, de espaço vazio, de pobres, de lugar de produzir aquilo que o meio urbano não consegue por falta de espaço. Ou seja, deixa de ser espaço de atividade agrícola e passa a ser considerado sob três aspectos importantes. Primeiro, o novo rural é visto como um lugar de relações e convivência com a natureza, do contato mais imediato com o meio natural. Lugar onde as relações entre seus componentes não podem ser completamente condicionadas pela ação humana (KUHN, 2015; ABRAMOVAY, 2000a).

O segundo ponto de mudança redefine o rural como área de reduzida densidade populacional, lugar onde as pessoas, a terra e outros recursos são localizados em espaço aberto, dispersas. Lugar também onde as famílias conhecem-se intimamente, se auxiliam em tempos de necessidade e confiam uns nos outros para cooperar. As pessoas socializam e constroem 
redes de vizinhos em que resistem ao processo de individualização e atomização social (ABRAMOVAY, 2000a).

O terceiro ponto é caracterizar o rural como inserido nas dinâmicas urbanas. Redes mercantis, sociais e institucionais se estabelecem entre o rural e o urbano, pois não há isolamento absoluto entre os espaços rurais e as áreas urbanas. O bem estar econômico das áreas rurais depende, portanto, de áreas mais densamente povoadas e o desenvolvimento rural não pode ser dissociado do desenvolvimento urbano (KUHN, 2015; ABRAMOVAY, 2000a; STRASSBURG et al., 2015).

Segundo Kageyama (2004), as propriedades rurais caracterizadas como supérfluas no paradigma da modernização podem assumir novos papeis no desenvolvimento rural, como administração da paisagem, conservação da natureza, agroturismo, agricultura orgânica, produção de especialidades regionais, vendas diretas, entre outras.

A criação de fontes de renda não-agrícola para as famílias não visa substituir a atividade agrícola, mas servir para sua viabilização. A possibilidade de diversificar as fontes de renda pode vim de características do local e de características interna das famílias. A motivação para desenvolver atividades rurais não-agrícolas vem da lucratividade, capacidade das famílias para assumir tais atividades, ou dos fatores de expulsão da agricultura como más colheitas, ausência de seguros para as safras ou crédito, risco da atividade, entre outros (STRASSBURG et al., 2015).

Dessa forma, pode-se caracterizar o desenvolvimento rural como um conjunto de ações e práticas que visam reduzir a pobreza rural. Estimula um processo de participação que empodera os trabalhadores, para que sejam os protagonistas do seu modo de viver e trabalhar, para que sejam autônomos, dominem tecnologias, tomem decisões, para que busquem através do seu esforço e disposição ampliar as possibilidades de sua reprodução (SCHNEIDER, 2004).

Kuhn (2015) também define desenvolvimento rural como o aumento das possibilidades de escolha das pessoas que residem em ambientes rurais, a qual são constituídos de relações socioeconômicas, geográficas e culturais. Se dá pelo aproveitamento da paisagem, utilização e preservação dos aspectos relacionados a natureza para melhorar a qualidade de vida no ambiente rural.

As medidas de diversificação da produção e aproveitamento de atividades não-agrícolas intangíveis como culinária, cultura, turismo e geração de energia, trazem além da geração de renda a minimização das pressões ambientais, que associa a expansão da agricultura ao aquecimento global e à perda da biodiversidade. Além disso, implicam na segurança alimentar. Essa nova ideia de desenvolvimento é a gênese entre preservação ambiental, redução da pobreza e acesso à alimentação (STRASSBURG et al., 2015).

\section{CAPITAIS INTANGÍVEIS E A ATUAÇÃO DOS ATORES LOCAIS PARA O DESENVOLVIMENTO RURAL}

Este capítulo apresenta seis estudos de caso que evidenciam a iniciativa, atuação e empreendedorismo de atores e instituições locais bem como os capitais intangíveis presentes nas comunidades, fatores que em conjunto contribuem para o desenvolvimento rural.

\section{a. Turismo espiritual em São João dos Mellos- RS}

A comunidade de São João dos Mellos fica situada na região Centro-Ocidental do estado do Rio Grande do Sul, a $30 \mathrm{~km}$ de Júlio de Castilhos, a qual é distrito desde 1991, e a $77 \mathrm{~km}$ de Santa Maria. É um núcleo agrícola com aproximadamente 250 habitantes que vem se destacando na atividade turística. As famílias que residem nesta comunidade apresentam 
hábitos culturais tais como gastronomia, vocabulário, arquitetura, religiosidade e manejo rural com fortes influências tradicionais de imigrantes italianos (BENETTI; DEPONTI; HAMMERL, 2015).

A partir da década de 1960 a agricultura até então de subsistência se transformou em moderna com o uso de máquinas, insumos e implementos agrícolas. Os principais cultivos na comunidade são milho, feijão, fumo, batata, soja e arroz e predominam unidades familiares de produção (BENETTI; DEPONTI; HAMMERL, 2015).

A comunidade vem passando desde a entrada do século XXI pela redução da renda rural em virtude da crise do setor aliado aos altos preços dos insumos. Nessa situação muitas famílias têm deixado a comunidade em busca de melhores rendas no meio urbano ou incentivando os filhos a buscarem capacitação e empregos nos grandes centros (BENETTI; DEPONTI; HAMMERL, 2015).

O turismo em São João dos Mellos surgiu em decorrência de um atrativo cultural existente no local, o Jardim das Esculturas, um acervo com cerca de 600 esculturas em arenito criados pelo morador Rogério Bertoldo, que as mantém dentro de casa e no jardim de sua residência. As esculturas refletem elementos do cotidiano, animais, artes marciais, faces humanas e outros elementos ligados à natureza. O local é aberto a visitação, e os visitantes podem desfrutar das obras de arte além de áreas floridas, gramados, trilhas, sombras e áreas de descanso, energização e meditação (BENETTI; DEPONTI; HAMMERL, 2015; CARGNIN; BECKER, 2017; JARDIM DAS ESCULTURAS, 2020).

As esculturas aliadas à paisagem rural tem atraído diversos públicos à comunidade, especialmente praticantes de yoga, trilheiros e apreciadores de arte. Desde 2008 a visitação tem sido organizada profissionalmente para recepção dos visitantes com o cercamento do jardim, cobrança de taxa de visitação, abertura de um restaurante vegano, projeto de divulgação e organização de excursões para atrair os turistas (BENETTI; DEPONTI; HAMMERL, 2015).

A preocupação dos moradores e do escultor com o desaparecimento da comunidade, em decorrência do processo de êxodo rural e envelhecimento da população, levou Rogério, que possui forte vínculo com a comunidade de São João do Mellos, a propor em 2010 uma parceria com todas as famílias da comunidade para que todos pudessem se beneficiar do fluxo de visitantes. A parceria "comunidade-jardim" foi uma estratégia para manter a comunidade "viva" no sentido econômico gerando mais renda para todos, mas também tornar o lugar reconhecido, reafirmar o saber-fazer-local, símbolos e identidades do território. Os moradores aderiram a ideia e criaram em 2010 a Associação Pró-Turismo de São João dos Mellos (APTSJM) (BENETTI; DEPONTI; HAMMERL, 2015).

O papel da associação era a viabilização da articulação da comunidade com o poder público, empresas e visitantes. As principais ações foram à busca de apoio da Prefeitura Municipal de Júlio de Castilhos, parceria com agências de turismo de Santa Maria, contatos com a EMATER, dentre outras, com o objetivo de aprimorar o turismo local. Uma importante ação foi a parceria com o Serviço Nacional de Aprendizagem Rural (SENAR) buscando capacitação para as famílias. Dentre os principais cursos frequentados foram gestão do turismo, higiene, segurança alimentar, gastronomia e gestão da jardinagem (BENETTI; DEPONTI; HAMMERL, 2015).

As famílias ofertam hospedagem alternativa dentro de suas próprias casas, pratos típicos, artesanatos e produtos alimentícios coloniais como geléias, pão e destilados para venda em postos de paradas dos visitantes. A renda é distribuída de forma igualitária entre os participantes (BENETTI; DEPONTI; HAMMERL, 2015).

Nos finais de semana o Jardim das Esculturas recebe em média 500 visitantes e ao menos uma vez por mês é promovido eventos como práticas de yoga, caminhadas e atividades ao ar livre. Atualmente verificou-se que a associação Pró-Turismo não está mais ativa, mas 
algumas propriedades próximas do jardim ainda fornecem hospedagem e alimentação principalmente para pessoas que participam dos eventos que muitas vezes se estendem por vários dias. Segundo a esposa do proprietário, que administra o jardim, o restaurante vegano e recepciona os visitantes, o turismo vem refletindo positivamente na comunidade dando mais visibilidade e instigando os demais morados a cuidarem do jardim, de suas propriedades e a valorizar mais o local (JARDIM DAS ESCULTURAS, 2010; CARGNIN; BECKER, 2017).

O turismo local de São João dos Mellos ainda carece de mais infraestrutura, tanto dos governantes, como acesso ao local, sinalização, mas também de empresários e da comunidade para complementar os serviços prestados, como hospedagem (CARGNIN; BECKER, 2017).

O caso de São João dos Mellos retrata o empreendedorismo de um ator local que aproveitou seu dom e gosto pela cultura para desenvolver uma oportunidade de negócio inovadora, que é o turismo espiritual, aliada a paisagem rural para gerar renda e emprego, além de trazer valorização e visibilidade para a comunidade local. A prática associativa deixou de existir na comunidade e para trabalhos futuros fica a sugestão para estudo da motivação e as implicações desse fato para o desenvolvimento da região.

\section{b. Feira Corujão em Rio Claro-SP}

Segundo estimativas do IBGE de 2019, Rio Claro, município do interior paulista, possui 206.424 pessoas, é caracterizada como cidade média e possui em seu histórico aspectos fortes da ruralidade em sua formação, como a produção cafeeira e canavieira. Atualmente a economia gira em torno dos serviços e indústria, respondendo a agropecuária com apenas $0,75 \%$ do Valor Adicionado Bruto (VAB) de 2017. (IBGE, 2020a; BORTOLIN; MURBACH; LUCIANO, 2018).

Uma das mais tradicionais feiras da agricultura familiar de Rio Claro-SP é a Feira Corujão que é realizada duas vezes por semana no bairro Vila Martins. A feira tem como objetivo valorizar o produtor rural e incentivar o comércio e a produção agrícola local. Os consumidores encontram produtos de qualidade, agroecológicos e com preços acessíveis como frutas, verduras, legumes, cachaça artesanal, embutidos, pães, doces, lanches, tortas e peças de artesanato (LUCIANO, 2017).

A feira foi criada em 2012 através da iniciativa da Secretaria Municipal da Agricultura, Abastecimento e Silvicultura de Rio Claro que convocou produtores rurais para reuniões com o objetivo de resgatar a prática das feiras livres que estavam sendo esquecidas pela população. Para a feira poder ser viabilizada, foi criada a Associação dos Produtores Familiares de Rio Claro, que se tornou cooperativa em 2014. Os agricultores passaram a se engajar na iniciativa e foram convidando mais agricultores. No início a feira contava com 5 produtores e atualmente a cooperativa tem mais de 40 agricultores associados e participantes (BORTOLIN; MURBACH; LUCIANO, 2018).

Após formalização a cooperativa passou a participar do Programa Nacional de Alimentação Escolar (PNAE) e do Programa de Aquisição de Alimentos (PAA), programas federais que destinam $30 \%$ dos recursos para aquisição de alimentos da agricultura familiar para escolas e demais instituições (LUCIANO, 2017).

A feira acontece em espaço público e a Secretaria Municipal da Agricultura, Abastecimento e Silvicultura oferece, além do local, as bancas para venda dos produtos, energia elétrica e água. Também colabora para divulgação da feira com panfletos, reportagens em jornais, além da parceria para realização anualmente da festa do agricultor. Os produtores recebem ainda capacitações e assistência técnica para que possam desenvolver a atividade agrícola dentro da propriedade, ajudando a agregar valor à sua produção (LUCIANO, 2017). Os produtores, assim, aliam seu saber local e cultural com capacitações e treinamento, visando ampliação do capital humano local. 
Segundo pesquisa realizada por Luciano (2017) com produtores familiares que vendem produtos na feira do Corujão, o principal motivo que os levou a participarem foi a possibilidade de venda da produção, incentivo dos órgãos públicos, o fortalecimento que a feira vem alcançando, a complementação de renda e o incentivo dos demais agricultores participantes. A feira se tornou de fundamental importância para a manutenção da renda das famílias visto que para a maioria dos produtores $25 \%$ de sua renda advém da feira e é o local de principal comercialização de sua produção. Se percebeu que a motivação para a prática colaborativa foi a possibilidade de ganhos financeiros. A iniciativa e persuação de atores e instituições locais foram capazes de canalizar positivamente elementos antes latentes ou dispersos no território para gerar incremento de renda.

O caso da Feira Corujão mostra as ações do poder público como fomentador e articulador de políticas de desenvolvimento, no qual lançou a ideia da feira, instigou a cooperação e os demais atores locais responderam com a participação e engajamento. A Secretaria Municipal da Agricultura, Abastecimento e Silvicultura de Rio Claro exerce peso sobre os objetivos e interesses dos agricultores, facilitando a cooperação e a manutenção da feira por todo esse tempo, sendo um evento muito importante pra obtenção de renda e para permanência deles no campo.

\section{c. Turismo rural no Vale do Paraíso- RS}

Localizado a aproximadamente $25 \mathrm{~km}$ de Torres- RS, o município de Três CachoeirasRS é um dos municípios do Litoral Norte gaúcho sem acesso ao mar, que tem no ecoturismo e no turismo rural importante fonte de renda, aproveitando assim o verde de suas matas nativas, águas límpidas e a cultura colonial para atrair turistas (PORTO ALEGRE 24 HORAS, 2019).

O destaque no turismo da cidade é o Vale do Paraíso, roteiro de turismo rural instalado no distrito de Morro Azul, a $13 \mathrm{~km}$ de Três Cachoeiras. O distrito tem aproximadamente 800 habitantes e no roteiro é possível ver um cenário típico de interior com traços do processo de colonização italiana e alemã que se instalou na região há quase dois séculos (PORTO ALEGRE 24 HORAS, 2019).

Os turistas visitam 8 propriedades e pagam taxas de visitação a cada uma. O roteiro inclui passagem por um engenho de cachaça, moinho d'água, mostra de artesanato regional, passeios a cavalo e trilhas que levam a cachoeiras. Os visitantes podem fazer refeições como café rural e almoço com produtos da cultura e adquirir produtos coloniais como rapadura, amendoim, cachaça, açúcar mascavo entre outros (PUGEN; AGUIAR; OLIVEIRA, 2013).

A criação do roteiro Vale do Paraíso foi uma iniciativa de um grupo de 10 moradores do local, todos com laços de parentesco, pertencentes ao Clube Social e Esportivo Vera Cruz, que se sentiram motivados a mostrar e promover a cultura da região dada as belezas naturais, a história dos tropeiros que partiram da região em direção à serra gaúcha e as atividades relacionadas a agricultura. Além disso, estavam enfrentando o enfraquecimento do Clube em virtude de muitos membros estarem migrando para as áreas urbanas (PUGEN; AGUIAR; OLIVEIRA, 2013; PUGEN, 2016).

O grupo passou a fazer reuniões na sede do distrito e foram sendo convidados e apontados os proprietários que possuíam atrativos naturais ou culturais e que tinham interesse no projeto. Mais pessoas se engajaram na ideia e partiram em busca de apoio técnico na faculdade de turismo da Universidade Luterana do Brasil (ULBRA), Campus de Torres, juntamente com Emater e o Sindicado Rural (atas datam de 2001). A partir de então, alguns proprietários engajaram-se no projeto de desenvolvimento do turismo rural e passaram a organizar-se para receber visitantes. Aos poucos os participantes foram fazendo cursos de 
turismo rural, boas práticas de cozinha entre outros, qualificando o serviço prestado aos turistas (PUGEN; AGUIAR; OLIVEIRA, 2013; PUGEN, 2016).

A criação do roteiro do turismo rural do Vale do Paraíso contribuiu também para unir os dois grupos étnicos, alemães e italianos, que antes apresentavam uma certa divisão, em que um grupo não comparecia nos eventos promovidos pelo outro. Com o roteiro turístico todos viram possibilidades de incrementar suas rendas (PUGEN, 2016).

Em 2005 outras parcerias importantes foram alcançadas pelos moradores: o Serviço Social do Comércio (SESC) e agências de turismo de Torres. Esta última passou a levar semanalmente ônibus lotado de visitantes para o roteiro. Em algumas ocasiões os agricultores receberam a visita de 200 pessoas em um só dia (PUGEN, 2016).

Os membros do roteiro do Vale do Paraíso possuem pequenas propriedades, têm como renda principal atividades agrícolas como cana-de-açúcar, banana e também criação de gado. O trabalho agrícola é feito por membros das famílias e o turismo é uma atividade secundária. As atividades de turismo se misturam com o local de residência e de trabalho na agropecuária (PUGEN, 2016).

Os produtores entrevistados por Pugen, Aguiar e Oliveira (2013) relatam que a atividade turística agregou valores à renda familiar e que uma atividade (agropecuária) depende da outra (turismo). Relatam também que ocorreu um pequeno aumento no número de empregos, já que cada produtor contratou um funcionário fixo e em dias com agenda cheia contratam diaristas para receber os visitantes.

O caso do Vale do Paraíso retrata a existência de capital social informal em uma comunidade, em que um grupo de pessoas com relações familiares, de vizinhança e amizade percebem a decadência de uma estrutura social juntamente com o êxodo rural, se inconformam com a situação e buscam alternativas, para junto com as potencialidades naturais do local, desenvolver o turismo rural. Os integrantes buscaram capacitar o capital humano presente no local, fizeram parcerias com outras instituições locais e desenvolvem o que atualmente se chama de novo rural. As atividades desenvolvidas na agricultura se entrelaçam com a nova fonte de renda e emprego, o turismo, e contribuem para a manutenção da cultura e biodiversidade da região.

\section{d. Enoturismo no Vale dos Vinhedos- RS}

O Vale dos Vinhedos constitui a principal rota enoturística do Brasil, reconhecido pela qualidade dos vinhos e gastronomia típica italiana a qual tem se destacado pela atração de um número significativo de visitantes (XAVIER, 2016).

A região Vale dos Vinhedos está localizada na Serra Gaúcha, a pouco mais de $120 \mathrm{~km}$ de Porto Alegre, Possui dois referenciais: um político-administrativo, que se refere ao Distrito do Vale dos Vinhedos pertencente ao município de Bento Gonçalves; e outro referente à indicação geográfica, que se refere à parte dos municípios de Bento Gonçalves (60\%), Garibaldi (33\%) e Monte Belo do Sul (7\%). Na região se desenvolveu uma agricultura de subsistência e cultivo de videiras para produção de vinhos (SIEDENBERG; THAINES; BAGGIO, 2017).

Na década de 1970, em decorrência da queda do preço da uva, os produtores do Vale dos Vinhedos deixaram de vender a uva para grandes empresas e passaram a utilizar a produção para fazer seu próprio vinho e comercializá-lo diretamente, com o intuito de ampliar os ganhos, criando-se assim pequenas vinícolas na região (ZANCAN, 2010; XAVIER, 2016).

A entrada de empresas internacionais no setor, como Chandon, Maison Forestier e Martini, levou os produtores familiares a enfrentar dificuldade em competir com esses produtos de qualidade maior. Na buscar de alternativas para melhorar a qualidade dos produtos, passaram a se reunir em cooperativas. Neste momento os filhos dos produtores, que haviam saído da 
região para qualificação no setor do vinho, retornaram as propriedades (ZANCAN, 2010; XAVIER, 2016). Esse fato reflete que a motivação para a cooperação dos produtores de vinho veio através de problemas, mas os atores locais tomaram consciência e se empenharam em resolvê-los.

Alguns produtores de vinho, dentre os principais Juarez Valduga, Candido e Miolo, descontentes com as representações do setor, se reuniram e passaram a propor e discutir a formação de uma associação com o objetivo não só de produzir com mais qualidade, mas dar visibilidade e escoamento da produção, transformar a região em atração turística e buscar a denominação de origem para os produtos do Vale. As reuniões ocorreram no decorrer de 1993 e 1994. Os produtores buscaram apoio da Universidade de Caxias, Universidade do Rio Grande do Sul, SEBRAE e da Empresa Brasileira de Pesquisa Agropecuária (Embrapa) e em 21 de fevereiro de 1995 foi formalizada a Associação dos Produtores de Vinhos Finos do Vale dos Vinhedos (APROVALE) inicialmente com a participação de 6 vinícolas (ZANCAN, 2010; XAVIER, 2016).

Com o intuito de promover o enoturismo e divulgar a região, a APROVALE em 1998 passou a trabalhar para a solicitação da Indicação de Procedência (IP). O reconhecimento geográfico do espaço junto ao Instituto Nacional de Procedência Intelectual (INPI) veio em 2002 e com isso a região passou a ter um Selo de Controle Vale dos Vinhedos que é exclusivo para vinhos e espumantes elaborados a partir de uvas cultivadas no Vale dos Vinhedos e engarrafadas na origem. O selo tem reconhecimento da União Europeia podendo os produtores exportar os produtos (XAVIER, 2016).

Em 2010 a APROVALE protocolou pedido de Denominação de Origem (DO) do Vale dos Vinhedos ao INPI concedida em 2012. Este selo é mais criterioso e relaciona o produto com qualidade, sabor, cultura e a história da região e apresenta regras de cultivo e processamento mais rígidos (XAVIER, 2016).

Em 1995 a região produzia 600 mil litros de vinhos finos, em 2006 passou para 7 milhões e em 2010 para 10,1 milhões de litros. Em 2001 recebeu 12.600 visitantes, em 2006 recebeu 115 mil turistas e no primeiro semestre de 2019 recebeu 255 mil visitantes, fatos que demonstram a importância da união dos produtores, do IP e do DO para a consolidação do enoturismo na região. $\mathrm{O}$ impulso do turismo com os reconhecimentos do INPI fez emergir a necessidade de ofertas de serviços complementares na região. Atualmente a APROVALE conta com 22 vinícolas associadas e 40 empreendimentos de outras áreas que apoiam o turismo como hotéis, pousadas, restaurantes, queijarias, ateliês, entre outros (APROVALE, 2020).

Pode-se concluir que a interação entre os produtores de vinho possibilitou a criação da APROVALE conferindo profissionalismo, empreendedorismo e inovação aos produtos e serviços prestados. A rede de relacionamentos existentes entre os atores envolvidos no processo de governança da APROVALE possibilitaram a alteração dos métodos de produção, a melhoria da qualidade dos produtos e o sucesso da região no enoturismo (XAVIER, 2016).

A APROVALE tem inúmeros desafios pela frente, entre eles preservar a identidade cultural regional, manutenção da consciência cooperativa entre os membros e buscar melhor infraestrutura turística. Sua atuação tem sido muito importante na região, pois o enoturismo manteve a população na zona rural, vem gerando novas vagas de empregos, valorização de imóveis, acréscimo na renda e incentiva os produtores a investirem em seus negócios (SIEDENBERG; THAINES; BAGGIO, 2017).

As instituições locais do Vale dos Vinhedos, motivadas por uma insatisfação e também por oportunidades de negócios, se reuniram na associação APROVALE, que através da cooperação, motivação e engajamento dos atores, obteve sucesso, cresceu e criou uma rede de poder, tornando possível o enfrentamento de incertezas, compartilhamento de saberes, pleito de melhor infraestrutura perante o poder público e o reconhecimento da identidade do território. 


\section{e. Agroindústrias familiares de Melado em Capanema - PR}

Capanema é um município paranaense constituído em 14 de novembro de 1951, localizado às margens do Rio Iguaçu, a $350 \mathrm{~m}$ de altitude. Faz fronteira com a Argentina e com o Parque Nacional do Iguaçu, que abriga as Cataratas do Iguaçu. Segundo estimativas do IBGE em 2019 possuía 19.124 habitantes (IBGE, 2020b).

A economia do município é baseada na agricultura e a cana-de-açúcar se destaca como uma das principais atividades agrícolas do município. Há um esforço local para oferecer novas alternativas de produção para manter o homem no campo, visto que o espaço é ocupado pela agricultura familiar. Alguns subprodutos de grande destaque no município são o açúcar mascavo e o melado (TOMASETTO; FERRERA DE LIMA; SHIKIDA, 2009).

A cultura da cana-de-açúcar foi trazida para o Sudoeste paranaense pelos imigrantes, em sua maioria, alemães provenientes do Rio Grande do Sul e Santa Catarina. No início era uma atividade manual e de subsistência. A partir de 1970 a produção de cana e a fabricação de açúcar foi deixada de lado pelos produtores. No final da década de 1980 os produtores com o intuito de resgatar a cultura e tradição voltaram a produzir, principalmente o melado. Um produtor da região desenvolveu então uma máquina para bater o melado com um motor. Com o aparecimento de nichos de mercado para os produtos, a partir de 1995 teve início a produção em escala industrial se tornando uma alternativa para a pequena propriedade rural diversificar a renda e agregar valor à produção (MENEGUCE et al., 2008; SEBRAE, 2020).

Aproveitando a tradição dos produtores e as condições edafoclimáticas propícias para a cultura, (terreno pedregoso e o clima quente possibilitam um melado com sabor e cor diferenciado de outras regiões), as agroindústrias foram projetadas e construídas com o objetivo de facilitar o trabalho de transformação, aumentar a produtividade, melhorar a qualidade do produto final, criar novos empregos e dinamizar o desenvolvimento local (TOMASETTO; FERRERA DE LIMA; SHIKIDA, 2009).

Algumas agroindústrias, exemplo Manguaba e Pingo de Mel, se formaram através de associações de famílias que buscavam alternativa de renda na entressafra agrícola. Muitas agroindústrias diversificaram a produção com bolachas e cachaça e hoje a atividade é importante fonte de renda para as famílias, embora ainda seja uma atividade secundária (PERONDI; KIYOTA, 2002; TOMASETTO; FERRERA DE LIMA; SHIKIDA, 2009).

O processo de desenvolvimento na agroindústria de cana foi possível através dos incentivos à comercialização do produto pela Coordenação Regional de Associações (CRAPA), pelos incentivos ao associativismo e criação das agroindústrias, pela Prefeitura de Capanema e pelo apoio do Parque Nacional do Iguaçu, pois é uma das atividades indicadas para a área do entorno de uma unidade de conservação, por ser menos agressiva ao meio ambiente (TOMASETTO; FERRERA DE LIMA; SHIKIDA, 2009).

A prefeitura auxiliou no processo de repasse dos recursos estaduais, nos custos com projetos para construção de unidades de processamento e no registro das unidades aos órgãos responsáveis. Desde 1990, juntamente com a Emater, realiza a Feira do Melado, cartão postal da cidade, com objetivo de incentivar os produtores a profissionalizar a atividade (KIYOTA, 1999).

Os produtores recebem assistência constante de diversas outras entidades governamentais e não-governamentais, parceria importante para dar maior competitividade na comercialização. O Governo do Estado participa dando assistência por meio da Secretaria de Estado da Agricultura e Abastecimento (SEAB). O Instituto Paranaense de Assistência Técnica e Extensão Rural (INSTITUTO EMATER) colabora com técnicos atuando na agricultura orgânica. Outros órgãos que atuam na agricultura no Sudoeste do Estado são a Associação de 
Estudos, Orientação e Assistência Rural (ASSESOAR), Centro de Tecnologias Alternativas (CETAP), Centro Paranaense de Apoio ao Pequeno Agricultor (CAPA), Sistema de Cooperativas da Agricultura Familiar (COOPAFI), Universidades, Associações de Produtores Orgânicos, Associações de Consumidores e Empresas de Processamento e Comercialização (TOMASETTO; FERRERA DE LIMA; SHIKIDA, 2009).

Em 2005, a partir do Programa de Desenvolvimento do Turismo Sustentável no Entorno do Parque Nacional do Iguaçu desenvolvido pela Direção do Parque Nacional do Iguaçu, foi criado o roteiro de turismo rural Doce Iguassu, composto pelos segmentos ecoturismo, agroindústrias e produção orgânica de Capanema. O intuito do roteiro é incentivar o turismo como alternativa de crescimento econômico, estimular o desenvolvimento integrado dos municípios, promover a conservação ambiental e criação e fortalecimento de associações e cooperativas que objetivem a sustentabilidade de atividade turística. Também em 2005 foi criada a Associação Doce Iguassu, composta por proprietários de estabelecimentos e interessados no turismo (CANDIOTTO, 2011).

Atualmente o município conta com 8 agroindústrias e 16 produtores de cana que garantem 200 empregos diretos. Em 2015 a Associação de Turismo Doce Iguassu em parceria com SEBRAE protocolou junto ao INPI proposta para indicação geográfica do melado de Capanema (produtos com indicação geográfica elevam a reputação e os valores próprios da localidade onde foram produzidos) e o registro foi concedido em dezembro de 2019. Com o registro a expectativa é que a produção de melado dobre nos próximos anos, incentivando mais pessoas a ingressarem na atividade, mais investimentos para ampliar as agroindústrias familiares e com isso mais emprego, renda e desenvolvimento para o município (GLOBO RURAL, 2020; PARANÁ, 2020).

As agroindústrias familiares em Capanema apontam para a importância da diversificação da atividade, agregando valor aos produtos, gerando trabalho e renda e contribuindo para manter o homem no campo com maior qualidade de vida (TOMASETTO; FERRERA DE LIMA; SHIKIDA, 2009).

O caso de Capanema é um exemplo de capital institucional presente na comunidade. Os atores locais e as várias instituições que auxiliaram de alguma forma na criação das agroindústrias ou na comercialização, estavam em sintonia, foram capazes de realizar acordos e manter relacionamento com diversos contextos da região. Todos buscavam o mesmo objetivo e souberam aproveitar a potencialidade do local para gerar desenvolvimento rural.

\section{f. Turismo cultural rural Caminhos de Pedra- RS}

O roteiro Caminhos de Pedra fica localizado no Distrito de São Pedro, a 12 quilômetros do município de Bento Gonçalves, a qual pertence, na serra gaúcha, estado do Rio Grande do Sul. Se trata de um caminho de 15 quilômetros que acompanha um vale, cujo rio constitui o eixo principal de povoamento da região. No caminho é possível apreciar cultura, gastronomia e arquitetura italiana nos mais de 20 pontos de visitação e observação. São casas centenárias de pedra e incluem moinhos, cantinas coloniais, casas de massas caseiras, teares, casas de doces, entre outras (SOUZA; ELESBÃO, 2008).

A colonização do local teve início em 1876 e a comunidade se manteve próspera por ser uma rota de ligação entre as colônias vizinhas. Ao longo do trecho existiam várias construções comerciais como hotéis, ferrarias, serrarias e moinhos. Na década de 1970 com a criação da rodovia RSC 453, ligando os municípios de Bento Gonçalves, Farroupilha e Caxias do Sul, o fluxo foi desviado, ocasionando encerramento das atividades da maioria dos estabelecimentos comerciais do distrito, afetando negativamente a economia da comunidade. A grande parte da 
arquitetura das casas coloniais acabou por ficar conservada em virtude do baixo poder aquisitivo das famílias (SILVA, 2019).

O engenheiro Tarcísio Vasco Michelon, natural de Bento Gonçalves, filho de agricultores que migraram para a cidade, graduou-se em hotelaria e voltou à terra natal em 1980 para administrar um hotel de seu sogro a qual era natural do Distrito de São Pedro. Em 1987 encontrou-se com o arquiteto Júlio Posenato, um interessado pela imigração italiana no Rio Grande do Sul e defensor do patrimônio cultural, e passaram a pensar em ações para preservar a cultura italiana no município que esbarrava no desinteresse do poder público e na dificuldade de encontrar uma justificativa econômica para a manutenção das antigas construções pelos agricultores (SOUZA; ELESBÃO, 2008).

Juntos pensaram no turismo cultural rural como um meio de transformar o patrimônio arquitetônico e cultural de Bento Gonçalves em uma fonte de renda para as famílias ou uma forma de agregar valor aos produtos que já eram fabricados, projetando a preservação das construções antigas e da memória da população local de forma privada. Como primeira ação, mapearam o patrimônio arquitetônico do município em busca de um local apropriado para a ideia. Selecionaram o Distrito de São Pedro pelo acervo de alta qualidade, numeroso, com construções representativas da imigração italiana, concentrado em pequena área, de fácil acesso e proximidade da cidade, água em abundância e fauna e flora de exuberante beleza natural. $\mathrm{O}$ nome escolhido para o local foi Caminhos de Pedra devido a grande quantidade de casas de madeira com porão de pedra existentes no local, típicas da colonização italiana e pelo solo pedregoso (SOUZA; ELESBÃO, 2008).

O contato dos dois idealizadores com a população do distrito se deu através do sogro de Michelon, que era natural do local. A ideia do turismo inicialmente foi recebida com descrédito pelos moradores do local devido também a falta de recursos, Após meses de trabalho e persuasão dos empreendedores, a proposta começou a ganhar adeptos e os primeiros gastos foram bancados por Michelon. A ideia da preservação cultural aliada a ganhos financeiros encontrou terreno fértil nos agricultores que tinham na cultura seus maiores valores (SOUZA; ELESBÃO, 2008).

Algumas casas começaram a ser restauradas para serem abertas a visitação e no dia 30 de maio de 1992 o distrito recebeu o primeiro grupo de visitantes, provenientes de São Paulo que vieram através de uma agência de viagens e visitaram 4 localidades. Em 1997, devido ao sucesso do roteiro, com a assessoria do SEBRAE foi fundada a Associação Caminhos de Pedra. Em 1998 o Projeto Cultural Caminhos de Pedra passou a contar com a Lei de Incentivo à Cultura do Estado do Rio Grande do Sul (Lei 10.846 de 19/08/1996), passando a captar recursos de empresas locais. Através do projeto os moradores do distrito de São Pedro foram incentivados a reconstruírem a sua identidade valorizando alguns traços de suas tradições, com objetivo de compartilhar estas com os visitantes (MICHELIN, 2007; BONOTTO et al., 2018).

A principal atividade econômica das pequenas propriedades é o turismo, que possibilita criação de agroindústrias e estabelecimentos comerciais. A viabilização econômica do roteiro é sustentada por meio da venda aos turistas e à comunidade urbana dos produtos confeccionados artesanalmente nos estabelecimentos, além de taxas de visitação. A mão de obra é familiar e para não descaracterizar a vida no distrito, os moradores são incentivados a manterem a agricultura, especialmente a policultura de subsistência (SOUZA; ELESBÃO; SCHAIDHAUER, 2011).

Atualmente a Associação Caminhos de Pedra conta com mais de 100 associados. O roteiro é pioneiro no Brasil no segmento turismo cultural rural e recebe anualmente cerca de 60.000 turistas. Os próprios participantes do roteiro relatam que a atividade ajudou na melhoria da autoestima dos agricultores, aumentou a renda das famílias, possibilitou valorização cultural, maior integração da comunidade, permanência das famílias na região e criação de um vínculo 
para a sucessão familiar (BONOTTO et al., 2018; SOUZA; ELESBÃO; SCHAIDHAUER, 2011).

O Roteiro Caminhos de Pedra se tornou um sucesso no seguimento turismo cultural rural através dos atores sociais que tinham objetivos claros e visão empreendedora e com capacidade de mobilização social juntamente com o capital social presente na comunidade, como confiança e disposição para participar de ações coletivas. Além disso, é um exemplo claro de pluriatividade do meio rural, em que as atividades não agrícolas, atreladas às potencialidades locais, viabilizam a atividade rural e transformam as pequenas propriedades rurais em importantes protagonistas do desenvolvimento rural.

\section{CONSIDERAÇÕES FINAIS}

No desenvolvimento rural, o território surge como estratégia ativa, são valorizados os recursos locais e engloba aspectos sociais, culturais, naturais, técnicos, econômicos e a participação da população. A agricultura familiar, portanto, é vista não apenas como uma unidade produtiva, mas uma unidade social (NATÁRIO; BRAGA; REI, 2010).

As famílias do novo rural buscam sua reprodução social com o desenvolvimento da pluriatividade combinadas com atividades não agrícolas, como culinária, artesanato, cultura e turismo.

O foco dos gestores públicos e instituições locais deve ser apoiar a produção familiar que vinculam a incorporação de novos valores intangíveis como o capital social, capital humano, capital cívico, capital institucional e empreendedorismo, que constituem fatores de produção altamente decisivos.

Neste contexto, o objetivo do trabalho foi reunir exemplos empíricos que mostram a atuação e contribuição dos atores locais e a presença dos capitais intangíveis em diversas comunidades brasileiras.

O turismo espiritual desenvolvido na comunidade de São João dos Mellos-RS, o turismo rural no Vale do Paraíso- RS e o turismo cultural Caminhos de Pedra- RS são exemplos de iniciativas e empreendedorismo da população local que contribuíram para o desenvolvimento dessas regiões. Foram motivados por possibilidade de negócios lucrativos, capacidade para assumir as atividades e fatores de expulsão da agricultura, como queda de renda, Os empreendedores do território visualizaram oportunidades de negócios, mobilizaram recursos e desenvolvem ações para alcançá-las.

A Feira Corujão em Rio Claro- SP, o Enoturismo no Vale dos Vinhedos- RS e as Agroindústrias de Capanema-PR retrataram iniciativa, ação e articulação de instituições locais, como poder público e associação de moradores, empenhados para promover projetos que diversifiquem a renda das famílias e as mantenham no campo.

Todas as ações promovidas nessas comunidades, seja por iniciativa de pessoas da sociedade civil ou instituições locais, hesitaram porque tiveram disposição, engajamento, cooperação, confiança e trocas de informações entre os agentes sociais. As ações não vieram do alto para baixo, mas aproveitaram o potencial do território, como cultura, hábitos, paisagem, gastronomia e arquitetura, estando em sinergia com a base social e cultural já existente

Em todos os casos pode-se observar que as famílias domiciliadas nos espaços rurais não estão abandonando as atividades agrícolas, mas pelo contrário, se observa a presença da diversificação e pluriatividade que contribui para aumento de renda, geração de empregos e permanência no campo.

Como limitação do estudo pode-se apontar a dificuldade de encontrar estudos publicados com detalhes sobre as interações e iniciativas dos atores locais. Não se pretende esgotar as discussões sobre o tema e sugere-se como estudos futuros relatar o protagonismo dos 
atores locais e a importância do capital social e institucional para outras regiões e atividades brasileiras além de um estudo aprofundado sobre as políticas públicas voltadas ao tema.

\section{REFERÊNCIAS}

ABRAMOVAY, R. Funções e medidas da ruralidade no desenvolvimento contemporâneo. Rio de Janeiro: IPEA, Texto para discussão 702, 2000a.

ALVES, A. F. Do desenho à implementação de projetos de desenvolvimento rural sustentável: interfaces e negociações no Projeto Vida na Roça (Paraná). 2008. 234 f. Tese (Doutorado em Ciências), Universidade Federal de Santa Catarina, Florianópolis, 2008.

ALVES, L. R. Região, Urbanização e Polarização. In: PIACENTI, C. A.; FERRERA DE LIMA, J.; EBERHARDT, P. H. de C. (Org). Economia e Desenvolvimento Regional, Foz do Iguaçu: Editora Parque Itaipú, v. 01, p. 41-51, 2016.

BENETTI, J.; DEPONTI, C. M.; HAMMERL, P. C. In: Seminário Internacional sobre Desenvolvimento Regional, 7, 2015. Rio Grande do Sul, UNISC. Anais eletrônicos... Disponível em: <https://online.unisc.br/acadnet/anais/index.php/sidr/article/view/13271. Acesso em 22 jan. 2020.

BONOTTO, C. et al.. Desenvolvimento rural da região dos Caminhos de Pedra, no município de Bento Gonçalves/RS-Brasil. COLÓQUIO-Revista do Desenvolvimento Regional, v. 15, n. 1, p. 1-15, 2018.

BORTOLIN, B. C.; MURBACH, B. A.; LUCIANO, W. R. Aspectos da ruralidade: a permanência e o novo rural no município de Rio Claro-SP. Geografia, v. 43, n. 1, p. 151-161, 2018.

BRAGA, T. M. Desenvolvimento local endógeno: entre a competitividade e a cidadania.

Revista Brasileira de Estudos Urbanos e Regionais, n. 5, p. 23, 2001.

BRUM, Argemiro Luís. Desenvolvimento Regional: Uma nova fase. AgroANALYSIS, v. 23, n. 6, p. 38-40, 2003.

CANDIOTTO, L. Z. P. O roteiro de turismo rural "Doce Iguassu", município de CapanemaParaná-Brasil: gênese e desenvolvimento. Revista Geográfica de América Central, v. 2, n. 47E, 2011.

CARGNIN, D. M.; BECKER, E. L. S. Turismo espiritual: práticas e vivências na atualidade. Disciplinarum Scientia, v. 12, n. 1, p. 109-130, 2016

DRUCIAKI, F. P. Desenvolvimento Territorial: Conceito e Elementos. In: BIDARRA, B.; FERRERA DE LIMA, J.; VOLL, F. P. (Org.). Economia e Desenvolvimento Territorial. Foz do Iguaçu: Editora Parque Itaipu, p. 21-29, 2017.

FERREIRA DE LIMA, J. O Crescimento Econômico Territorial. In: BIDARRA, B.; FERRERA DE LIMA, J.; VOLL, F. P. (Org.). Economia e Desenvolvimento Territorial. Foz do Iguaçu: Editora Parque Itaipu, p. 17-20, 2017.

GLOBO RURAL. Certificação promete impulsionar produção de melado em Capanema, no PR. 2020. Disponível em:

https://revistagloborural.globo.com/Noticias/Agricultura/Cana/noticia/2020 
/01/certificacao-promete-impulsionar-producao-de-melado-em-capanema-no-pr.html. Acesso em: 27 jan. p2020.

IBGE- Cidades. Capanema- Paraná. Disponível em:

https://cidades.ibge.gov.br/brasil/pr/capanema/

panorama. Acesso em: 23 jan. 2020 b.

IBGE- Cidades. Rio Claro- São Paulo. Disponível em:

https://cidades.ibge.gov.br/brasil/sp/rio-

claro/pesquisa/38/47001?tipo=ranking\&indicador=46997. Acesso em: 23 jan. 2020a.

JARDIM DAS ESCULTURAS. 2020. Disponível em:

<https://www.jardimdasesculturas.com.br/>. Acesso em: 04 fev. 2020.

KAGEYAMA, A. Desenvolvimento rural: conceito e medida. Cadernos de Ciência \& Tecnologia, v. 21, n. 3, p. 379-408, 2004.

KIYOTA, N. Agricultura familiar e suas estratégias de comercialização: um estudo de caso no município de Capanema- Região Sudoeste do Paraná. 1999. 149 f. Dissertação (Mestrado em Administração Rural), Universidade Federal de Lavras, Lavras, 1999.

KÜHN, D. D. Desenvolvimento Rural: afinal, sobre o que estamos falando? Redes (St. Cruz Sul, Online), v. 20, n. 2, p. 11-30, 2015.

LIMA, A. C. da C.; SIMÕES, R. F. Teorias do desenvolvimento regional e suas implicações de política econômica no pós-guerra: o caso do Brasil. Belo Horizonte: UFMG/Cedeplar, Texto para discussão 358, 2009.

LUCIANO, W. R. Agricultura familiar no contexto da Feira do Produtor Rural Feira Corujão no município de Rio Claro-SP. 2017. 57 f. Trabalho de Conclusão de Curso (Bacharel em Geografia), Universidade Estadual Paulista Júlio de Mesquita Filho, Instituto de Geociências e Ciências Exatas, Rio Claro, 2017.

MENEGUCE, B. et al. Estudo de Caso na Agricultura Familiar: Agroindústrias de Derivados de Cana-de-açúcar. Instituto Agronômico do Paraná (IAPAR), Instituto Paranaense de Assistência Técnica e Extensão Rural (EMATER). Pato Branco, 2008.

MICHELIN, R. L. A construção das idéias de herança cultural, etnicidade e identidade na arena turística do roteiro cultural Caminhos de Pedra-RS. In: Seminário da Associação Brasileira de Pesquisa e Pós-Graduação em Turismo- ANPTUR, 4, 2007, Universidade de Caxias do Sul. Anais Eletrônicos... Caxias do Sul, UAM, 2007, v. 27, p. 1-13. Disponível em: https://www.anptur.org.br/anais/anais/files/4/57.pdf.

MULS, L. M. Desenvolvimento local, espaço e território: o conceito de capital social e a importância da formação de redes entre organismos e instituições locais. Revista Economia, Brasília, v. 9, n. 1, p. 1-21, 2008.

NATÁRIO, M. M.; BRAGA, A. M.; REI, C. A valorização dos recursos endógenos no desenvolvimentos dos Territórios Rurais. In: Congresso Luso-Brasileiro para o Planejamento Urbano, Regional, Integrado, Sustentável- PLURIS, 4, 2010, Universidade do Algarve. Anais Eletrônicos... Faro, Portugal, 2010. Disponível em:

http://pluris2010.civil.uminho.pt/congresso_actas_ID.html.

NAVARRO, Z. Desenvolvimento rural no Brasil: os limites do passado e os caminhos do futuro. Estudos avançados, v. 15, n. 43, p. 83-100, 2001. 
OLIVEIRA, D.; MELLO, M. A. Novas formas de inserção da agricultura familiar ao mercado como estratégia de desenvolvimento rural. In: $44^{\circ}$ Congresso da Sociedade Brasileira de Economia e Sociologia Rural (SOBER), Fortaleza, 23 a 27 de Julho de 2006.

PARANÁ, Governo do Estado. Secretaria da agricultura e abastecimento. 2020. Disponível em: http://www.agricultura.pr.gov.br/Noticia/Melado-de-Capanema-conquista-selo-dequalidade-geografica. Acesso em: 27 jan. 2020.

PERONDI, M. A.; KIYOTA, N. A Gestão na agroindústria familiar de qequeno porte de cana-de-açúcar: Evolução, desenvolvimento e desafios. In: MORAES, M. A. F. D. de; SHIKIDA, P. F. A. (Org.). Agroindústria Canavieira no Brasil. São Paulo, p. 354-367, 2002.

PIACENTI, C. A. O desenvolvimento endógeno das regiões. In: PIACENTI, C. A.; FERRERA DE LIMA, J; EBERHARDT, P. H. de C. (Org). Economia e Desenvolvimento Regional. Foz do Iguaçu: Editora Parque Itaipú, p. 122-142, 2016.

PIERUCCINI, M. A.; CORRÊA, W. K. Território, Economia e Análise Geográfica. In: BIDARRA, B.; FERRERA DE LIMA, J.; VOLL, F. P. (Org.). Economia e Desenvolvimento Territorial. Foz do Iguaçu, Editora Parque Itaipu, p. 12-16, 2017.

PORTO ALEGRE 24 HORAS. 2019. Disponível em: https://www.poa24horas.com.br/aproveite-o-final-do-calor-neste-lugar-maravilhoso-roteirovale-do-paraiso-morro-azul/. Acesso em: 20 jan. 2020.

PUGEN, B. Dar, receber, retribuir: práticas socioeconômicas no turismo rural. 2016. 168 f. Tese (Doutorado em Desenvolvimento Regional), Universidade de Santa Cruz do Sul, Programa de Pós-Graduação em Desenvolvimento Regional, Santa Cruz do Sul, 2016.

PUGEN, B.; DE AGUIAR, M. D. S.; OLIVEIRA, V. L. B. Vale do Paraíso: possibilidades e desafios de uma iniciativa endógena de turismo no espaço rural. Revista Brasileira de Ecoturismo (RBEcotur), v. 6, n. 3, p. 692-707, 2013.

RAIHER, A. P. Desenvolvimento Territorial: Uma Proposta Metodológica. In: BIDARRA, B.; FERRERA DE LIMA, J.; VOLL, F. P. (Org.). Economia e Desenvolvimento Territorial. Foz do Iguaçu: Editora Parque Itaipu, p. 36-46, 2017.

SEBRAE, Capanema- Melado e açúcar mascavo. 2020. Disponível em: https://www.sebraepr .com.br/origensparana/capanema-melado-e-acucar-mascavo/. Acesso em: 27 jan. 2020.

SHNEIDER, S. A abordagem territorial do desenvolvimento rural e suas articulações externas. Sociologias, n. 11, p. 88-125, 2004.

SIEDENBERG, D. R.; THAINES, A. H.; BAGGIO, D. K. Desenvolvimento regional sob a ótica do reconhecimento da indicação geográfica: o case do vale dos vinhedos, a partir da percepção dos atores sociais. Gestão \& Regionalidade, v. 33, n. 99, p. 4-20, 2017.

SILVA, D. da. De colonos do vinho a agricultores do turismo: a identidade em transformação no distrito de São Pedro, Bento Gonçalves (RS). 2019. 123 f. Dissertação (Mestrado em História), Universidade de Caxias do Sul, Programa de Pós-Graduação em História- Mestrado Profissional, Caxias do Sul, 2019.

SOUZA FILHO, J. R. Desenvolvimento regional endógeno, capital social e cooperação. Disponível em: 
http://www.yorku.ca/ishd/LEDCD.SP/Links\%20BQ/68_Desenvolvimento_regional endogeno_capital_social_coopera.pdf. Acesso em: 20 jan. 2002.

SOUZA, M.; ELESBÃO, I.; SCHAIDHAUER, M. Os benefícios do turismo rural: Caminhos de Pedra, Bento Gonçalves/RS. Rosa dos Ventos, v. 3, n. 2, p. 216-227, 2011.

SOUZA, M. de; ELESBÃO, I. A introdução de uma inovação social entre agricultores familiares: o turismo rural em dois roteiros do estado do Rio Grande do Sul, Brasil. In: Colóquio Ibérico de Estudos Rurais, 7, 2008, Coimbra, Portugal. Cultura, inovação e território. Anais eletrônicos... Coimbra: ESAC, 2008. Disponível em: https://www.lume.ufrgs.br/bitstream/handle 110183/30321/000678557.pdf?sequen. Acesso em: 28 jan. 2020.

STRASSBURG, U. et al.. Produção rural e segurança alimentar no Brasil. Revista Brasileira de Desenvolvimento Regional, v. 3, n. 1, p. 55-81, 2015.

TOMASETTO, M. Z. de C.; FERRERA DE LIMA, J.; SHIKIDA, P. F. A. Desenvolvimento local e agricultura familiar: o caso da produção de açúcar mascavo em Capanema-Paraná. Interações (Campo Grande), v. 10, n. 1, p. 21-30, 2009.

VALDUGA, V. O processo de desenvolvimento do enoturismo no Vale dos Vinhedos. 2014. 151 f. Dissertação (Mestrado em Turismo), Universidade de Caxias do Sul, Programa de Pós Graduação em Turismo, Caxias do Sul, 2014.

VIANA, G.; FERRERA DE LIMA, J. A teoria do crescimento econômico. Interações (Campo Grande), v. 11, n. 2, p. 137-148, 2010.

WESENDONCK, C. C. Desenvolvimento Territorial: Políticas Públicas e Governança. In: BIDARRA, B.; FERRERA DE LIMA, J.; VOLL, F. P. (Org.). Economia e Desenvolvimento Territorial. Foz do Iguaçu: Editora Parque Itaipu, p. 30-35, 2017.

XAVIER, T. R. Governança dos atores locais em um cluster turístico: a associação de produtores de vinhos finos do vale dos vinhedos (APROVALE). 2016. 236 f. Tese

(Doutorado em Administração), Universidade Federal de Santa Maria, Programa de PósGraduação em Administração, Santa Maria, 2016.

ZANCAN, C. Redes de cooperação: um estudo de relações interorganizacionais na associação dos produtores de vinhos finos do vale dos vinhedos (APROVALE). 2010. 288 f. Tese (Doutorado em Administração), Universidade de Brasília, Programa de Pós-Graduação em Administração, Brasília, 2010. 